\title{
Transgressão e pioneirismo nos estudos canadenses: viagem por mais de 40 anos de carreira de Zilá Bernd.
}

\author{
Entrevistadores: Entrevistador: Oscar Augusto Berg ${ }^{1}$
}

Submetido em 25 de novembro e aprovado em 14 de dezembro de 2018.

Entrevistar Zilá Bernd significa mergulhar em uma viagem de mais de quarenta anos entusiasmadamente investidos em compreender os percursos culturais e linguísticos das Américas. $\mathrm{O}$ empreendimento se revela tanto mais estimulante e exigente quanto se examina o extenso currículo da professora Bernd: bacharel e mestre em Letras pela Universidade Federal do Rio Grande do Sul, Zilá já era professora nesta instituição ao dar início aos seus estudos de doutorado, cursados na década de 1980 na Universidade de São Paulo, complementados pela realização de um pós-doutorado no departamento de Literatura Comparada da Université de Montréal, no Canadá.

O país canadense nunca mais abandonaria Zilá Bernd, que é, hoje, uma referência nacional e internacional em estudos canadenses, tendo sido responsável por trazer ao Brasil autoras e autores, teorias e incontáveis mitos e figuras dos imaginários coletivos do Canadá e do Caribe, em especial, das comunidades francófonas destes países. Em paralelo, temas como a literatura riograndense e afrobrasileira também permearam a carreira docente de Zilá Bernd, cuja extensão e qualidade ímpares mereceram o recebimento de distinções como o Prix du Gouverneur Général en Études Canadiennes e a Medalha Nobre Parceria da Embaixada do Canadá no Brasil, em comemoração dos 150 anos da Confederação canadense, além dos títulos de Officière de l'Ordre National du Québec e Officière des Palmes Académiques, oferecido pelo governo francês.

Assim, a entrevista a seguir, no lugar de focar em algum ponto em específico da carreira de Zilá, busca apresentar um sobrevoo completo sobre os temas mais importantes de sua obra. Para tanto, foi necessário levá-la a cabo em dois momentos, ambos realizados de maneira presencial ao longo do mês de novembro de 2018 no apartamento de residência de Zilá Bernd, na capital gaúcha. Destes, o primeiro processou-se de maneira mais livre, 
com a entrevistada tendo total liberdade de expressão e sendo convidada a aprofundar as suas considerações sobre algumas questões abordadas. A partir dele, foi possível formular as perguntas abaixo transcritas, que - tendo sido enviadas previamente à realização do segundo encontro - conduziram o segundo momento da entrevista.

A principal preocupação que guiou a condução da entrevista e sua posterior redação foi a de sublinhar o caráter pioneiro e, como mencionado pela própria entrevistada, transgressor da carreira de Zilá Bernd como o elo de ligação entre a multiplicidade de atividades que compõem o seu rico e extenso repertório intelectual.

Para muitas e muitos, inclusive para mim, Zilá representou a porta de entrada nos estudos canadenses e em todo o imaginário, todas as referências e descobertas que esta exploração - inter e transcultural, inter e transdisciplinar pelas Américas - abarca. Assim, esta entrevista faz às vezes também de um grande agradecimento por tudo aquilo que Zilá compartilhou conosco ao longo de toda a sua carreira, bem como pelo que ainda iremos aprender da pluma desta notável canadianista.

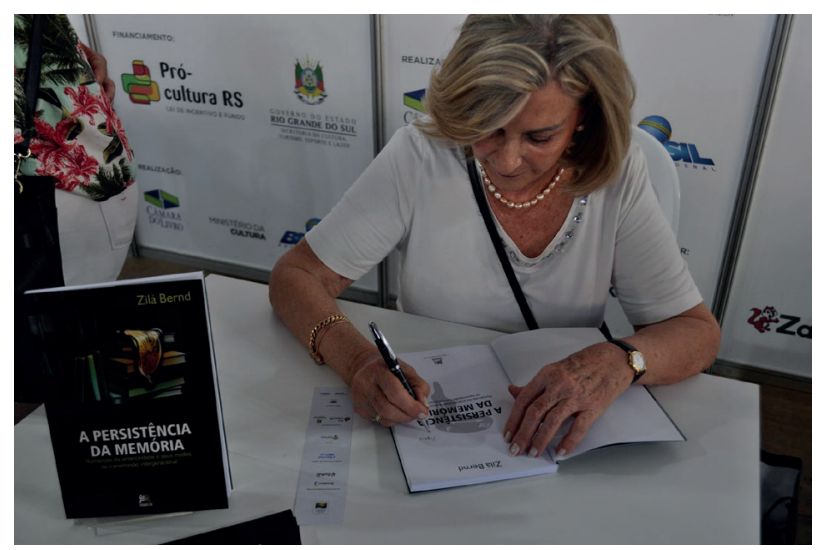

Zilá Bernd, na $64^{\mathrm{a}}$ Feira do Livro de Porto Alegre, em novembro de 2018 (Foto: Edições BesouroBox) 
OAB: Eu gostaria de iniciar esta entrevista evocando uma paixão em comum, a francofonia. De acordo com dados levantados em 2013 por Étienne Rivard para o Centre de la francophonie des Amériques, há, em nosso continente, 33 milhões de locutores de francês. Apesar de, hoje, a francofonia quebequense ser bem conhecida em nosso país, em função, entre outros, de seus trabalhos, outras comunidades francófonas das Américas continuam a ser pouco conhecidas ou mesmo ignoradas. Como se dava esta relação no início de sua trajetória acadêmica, havia espaços de contato ou estudos de expressões francófonas para além daquela da França?

ZB: Esta é realmente uma pergunta difícil de responder, pois, mesmo para nós que somos "francophones et francophiles", sempre foi difícil penetrar no espaço francófono, em especial em contextos minoritários. Até os anos 1980, os departamentos de letras eram completamente voltados ao estudo dos grandes clássicos da literatura francesa, como Balzac ou Proust. A produção em língua francesa desenvolvida fora da França era considerada nos compêndios de literatura francesa como "conexa e marginal" e ainda não tinha espaço no Brasil. Neste cenário, a minha abertura às literaturas e culturas francófonas do Caribe e do Quebec foi vista com desconfiança, até mesmo, como uma "traição" à França, a qual eu teria deixado de amar para buscar autores que que "ninguém conhecia". Três momentos marcaram esse processo: em primeiro lugar, a participação no V Congresso Mundial da Federação Internacional de Professores de Francês (FIPF) - Le français, une langue pour notre temps - organizado na Universidade Federal Fluminense, em 1981, que me colocou em contato com autores da francofonia do Caribe e com meu futuro orientador de doutorado, Ítalo Caroni. Em seguida, entre 1984 e 1988, o meu doutoramento na Universidade de São Paulo, com sanduíche na Université Laval sob a orientação do quebequense de origem haitiana Maximilien Laroche, que representou o pontapé inicial dos estudos daquele que se tornaria o meu grande tema: as relações literárias americanas por meio da francofonia. Por fim, já em 1992, o estágio de pósdoutorado no departamento de literatura comparada da Université de Montréal, onde eu pude abrir uma nova interface da literatura comparada que não fosse apenas aquela da França; uma interface americana por meio da língua francesa, em um momento no qual a interface dos comparatistas brasileiros era com as literaturas europeias. O sucesso 
dessa empreitada foi possível, em grande medida, pelo fato do Canadá ter mantido durante muitos anos uma distribuição regular de obras francófonas, o que nos permitiu gradualmente montar as bibliotecas dos Núcleos de Estudos Canadenses no Brasil, e de recursos financeiros para a realização de intercâmbios entre o Brasil e o Canadá e para o funcionamento da Associação Brasileira de Estudos Canadenses. Isso tudo antes de os orçamentos ministeriais canadenses terem sido drasticamente cortados ao longo da última década. Tentamos nos anos 1990, trabalhar nas universidades brasileiras com a rica produção cultural e literária francófona de diferentes países africanos, mas enfrentamos, à época, dificuldade em obter bibliografia. Mesmo no caso canadense, a penetração em núcleos francófonos minoritários, como em Saint-Boniface, na província do Manitoba, Moncton, Ottawa ou Saint John foi menos profícua, pelos obstáculos de acesso às produções, por questões geográficas ou pelas dificuldades na distribuição das editoras. Nesse sentido, nos limitamos às comunidades francófonas mais numerosas e com mais condições de divulgação de suas produções bibliográficas.

OAB: Bernard Andrès afirmou que, na literatura, a interamericanidade é a condição de uma comparação simétrica efrutuosa, sem hierarquizações, o que ele chamou de colateralidade. O que a entrada em cena das literaturas francófonas do Quebec e das Antilhas representou nas possibilidades de realização de estudos comparados?

ZB: Creio que a francofonia deu início a uma grande aventura que propiciou um melhor conhecimento das Américas através da língua francesa. Minha primeira experiência, em 1980, deveu-se a uma grande oportunidade que foi oferecida pelo governo do Quebec aos professores de francês das três Américas de irem visitar a província durante três semanas. O programa que se chamava "Trois semaines au Quebec" e fora iniciado em 1978 pelo Ministério de Relações Internacionais do Quebec, visava a uma sensibilização dos professores de francês de diferentes países das Américas que, até então, trabalhavam unicamente com a língua e cultura hexagonal. Essa vivência no Quebec fez com que abríssemos os olhos para um francês transplantado para as Américas e para um modo de estar no mundo americano que se exprimia em língua francesa. Para mim essa experiência foi definitiva, pois de retorno ao Brasil, propus a introdução de disciplinas de literatura 
e cultura quebequenses no currículo do programa de francês da Universidade Federal do Rio Grande do Sul, que envolvia, até então, unicamente tópicos da França. A partir disso, foi possível quebrar a grande alienação de que toda a cultura provinha da França, o que desvalorizava, até mesmo, nosso rico patrimônio cultural brasileiro. O que resultou dessa tão valiosa experiência? O primeiro ganho foi aprender a "deshierarquizar" as culturas, pois havia uma tendência a achar que o francês de França era mais "bem falado e mais culto" que o falado na província francófona do Canadá. Essa visada correspondia ao europeucentrismo dominante nas Américas que fazia com que considerássemos superior tudo que se localizava na Europa ou que tivesse obtido a chancela europeia como por exemplo as literaturas latino-americanas que só passamos a apreciar no Brasil depois de virar moda na Europa. O francês transplantado para a América tem suas diferenças assim como o português do Brasil difere do de Portugal e o inglês falado nos Estados Unidos tem traços distintos do inglês britânico. O segundo ganho foi abrir as portas a um comparativismo cultural e literário interamericano, olhando para o "perto" (a América) ao invés de olhar para o "longe" (a Europa). Assim pudemos encontrar processos de autonomização cultural semelhantes no Brasil, no Quebec e também nas Antilhas uma vez que os escritores deparavam-se com as mesmas dificuldades de nomear o continente americano utilizando-se de estruturas linguísticas estabelecidas para nomear fauna e flora europeias. Nesse sentido, concordo com Bernard Andrès quando ele fala de "comparação simétrica e frutuosa, sem hierarquização". Com o Quebec foi possível estabelecer um verdadeiro diálogo não-hierarquizado, rompendo com as trocas com a França que sempre foram hierarquizadas e assimétricas. Esse processo nos auxiliou a melhor entender nosso próprio patrimônio cultural, permitindo-nos descobrir semelhantes modos de autonomização literária do norte ao sul do continente americano.

OAB: A sua produção testemunha do desejo de estabelecer o diálogo entre o Brasil e o Quebec. Neste empreendimento, qual o papel exercido pelas perspectivas intercultural, multicultural e transcultural? Quais incentivos e barreiras impactaram o estabelecimento deste diálogo? 
ZB: De 1991 em diante quando os Núcleos de Estudos Canadenses se multiplicam, a interdisciplinaridade, para não falar em transdisciplinaridade, começa a difundir-se surgindo revistas como a Canadart (UNEB) e a Interfaces Brasil-Canadá, avaliada hoje com Qualis A2 em letras, B2 na área interdisciplinar. Essas publicações comprovam a permanência da pesquisa em Estudos Canadenses no Brasil, graças à tendência, presente em grande parte dos artigos, de associar aspectos ligados à diversidade cultural canadense à multi, inter e transdiciplinaridade e à multi, inter e trans culturalidade. $\mathrm{O}$ papel da Interfaces foi exponencial, pois com o tempo essa revista científica tornouse o ponto de encontro de pesquisadores das mais variadas disciplinas que olhavam os Estudos Canadenses de diferentes pontos de vista. O fato de ter sobrevivido depois do desaparecimento da maior parte dos núcleos de Estudos Canadenses que se espalhavam pelo Brasil e de permanecer pujante apesar do enfraquecimento da ABECAN, comprova seu relevante papel de lugar de memória dos estudos canadenses, servindo de estímulo a pesquisadores de diferentes áreas que têm nos Estudos Canadenses seu foco principal. Sabe-se que é requisito fundamental para os Estudos Canadenses o conhecimento de uma das duas línguas oficiais, ou, se possível, de ambas. No Brasil, essa questão do domínio do inglês e do francês ainda se põe como entrave ao seu pleno desenvolvimento. Embora não nos caiba falar do futuro dos Estudos Canadenses, consideramos, pela experiência destes últimos anos, após o corte drástico nas verbas de financiamento do ICCS-CIEC (International Council for canadian Studies), que, sem apoio institucional, houve grande perda de fôlego, pela falta das trocas que se realizavam nos congressos das associações nacionais que haviam se criado em muitos países em diferentes continentes. Ao todo, a importância do Quebec foi muito maior do que simplesmente conhecer uma outra literatura, uma outra cultura, mas de nos conscientizar de que não estávamos sós a buscar uma linguagem para nomear as experiências próprias à vida em uma sociedade do novo mundo e, com isso, nos ajudou a repensar a própria disciplina de literatura comparada e a nos repensarmos a nós mesmos.

A: Antes de se consolidar como uma referência mundial em estudos canadenses, você também havia se interessado sobre outros temas, em especial, a literatura afrobrasileira. Neste caso, a exemplo daquilo que foi necessário fazer para as literaturas 
francófonas das Américas, também foi preciso travar uma luta pela visibilidade destas produções?

ZB: Em primeiro lugar, agradeço tua generosidade, mas acho que estou longe de ser "referência mundial" em estudos quebequenses e/ou canadenses: acho que sou somente uma grande entusiasta e incentivadora destes estudos. Voltando à pergunta, à época em que iniciei o meu doutorado a então chamada literatura negra brasileira se encontrava totalmente fora da instituição literária brasileira, pois não detinha nenhuma editora, não estava em nenhuma livraria, biblioteca ou sala de aula, muito menos nas premiações. A definição de literatura afro-brasileira era aquela de uma obra feita por negros para falar sobre negros para negros, o que era algo que eu discordava. Eu acreditava - e sigo acreditando - que não podíamos “epidermizar” uma questão que é literária e que era preciso adotar outro critério. É aí que eu crio a definição de literatura negra como aquela onde existe um eu enunciador que se quer negro, que se reivindica como negro em primeira pessoa. Ou seja, um critério enunciativo, que exclui dessa literatura um autor como Castro Alves, o poeta da escravidão, que embora mulato, nunca se reconhece como negro, referindo-se sempre àqueles negros, mas que permite incluir autores como Luiz Gama, que se quer negro e se afirma como tal nos textos poéticos. Esta ideia pioneira está presente em minha tese de doutoramento, a partir da qual eu publiquei Negritude e literatura na América Latina, de onde derivei, mais tarde, duas antologias (BERND, 1992, 2011) que permitiram, enfim, aos professores trabalharem em seus cursos a literatura afro-brasileira. Felizmente, trinta anos após esta publicação, a situação mudou completamente, um dos autores que eu estudei, Domício Proença Filho é membro da Academia Brasileira de Letras, Conceição Evaristo recebeu o prêmio Jabuti e os livros de literatura afro-brasileira aparecem cada vez mais em resenhas e feiras de livros no Brasil e no exterior. Eu acredito que o meu trabalho contou para esta grande mudança.

OAB: Após mais de quarenta anos de carreira acadêmica, é possível identificar uma trama comum dentre as tantas temáticas que compõem a sua obra?

ZB: Pensando em sua pergunta sobre a diversidade de temáticas que já abordei em minhas pesquisas, penso que, apesar da aparente cacofonia discursiva, há um fio 
condutor a unir todas elas. Se meu roteiro intelectual pode aparentemente dar uma impressão um tanto caótica, há uma linha de força que, embora não evidente, existe. Em meus diferentes projetos - posso pensar em cinco grandes eixos de pesquisa - foi perseguido o que estava fora do cânone nos estudos sobre as questões identitárias. Deixando mais clara minha resposta, examino cada um destes eixos: (1) o estudo do “gaúcho a pé”, na literatura sul-riograndense, não era evidente, pois todos estavam à época estudando o gaúcho "monarca das coxilhas", glorioso montado em seu cavalo, que, em verdade, já não existia mais, pois fora expulso do campo pela mecanização do trabalho e partira a formar bolsões de miséria, originando os atuais sem terra. Nesse sentido, minha dissertação de mestrado sobre Cyro Martins representou uma dissidência com o regionalismo de base tradicional; (2) a pesquisa sobre literatura negra brasileira - até os anos 1980 - não ocupava nem notas de rodapé nas historiografias literárias brasileiras: a História concisa de Alfredo Bosi apresenta Luiz Gama, hoje considerado o fundador da consciência negra no Brasil, em nota de rodapé, deixando de mencionar outros poetas representantes do que hoje chamamos "literatura afro-brasileira". A definição enunciativa que eu propus transgredia aquela até então aplicada para delimitar as fronteiras desta literatura; (3) a literatura comparada tradicional foi criada para estudar as literaturas do centro e a "influência" que exerciam nas literaturas periféricas. Portanto, sempre tinhase que, necessariamente, passar pelo centro: inconcebível comparar literaturas ditas periféricas entre si; fazer dialogar literaturas do Brasil e do Quebec foi - nos anos 1990 quando publiquei Confluences littéraires Brésil-Québec; les bases d'une comparaison - algo pioneiro e totalmente subversivo em termos da literatura comparada tradicional. Participei da implosão do conceito tradicional e colonialista de literatura comparada e pela substituição por outro, que, no lugar da influência, passou a se interessar pela convergência; (4) os 4 dicionários de que fui organizadora (Figuras e mitos literários das Américas, Dicionário de mobilidades culturais, Glossaire des mobilités culturelles, Antologia de textos fundadores do comparativismo literário interamericano e Dicionário de expressões da Memória Social e dos bens culturais) procuraram igualmente estabelecer o princípio dos estudos culturais de analisar a mobilidade dos mitos entre as Américas, dando ênfase para figuras dos povos americanos e dos africanos, povos aqui trazidos na 
condição de escravos; portanto a perspectiva da americanidade estava sendo introduzida no Brasil, assim como os estudos culturais e literárias interamericanos; (5) nos estudos sobre a Memória, privilegiamos sobretudo questões marginais como o estudo dos rastros (vestígios memoriais): a memória como instrumento de revivescência das subjetividades em populações vítimas de dramas como, por exemplo, a Shoah e o tráfico negreiro e a pós-memória como o empenho da segunda e terceira geração das vítimas em construir narrativas dos fragmentos memoriais de seus antepassados através da comparação entre literaturas das Américas. Assim, o fio condutor está em iluminar os desvãos da cultura e da literatura, adotando-se sempre a perspectiva interamericana, a qual constitui, hoje, um Grupo de Trabalho da ANPOLL (Associação de professores de língua e literatura no Brasil) intitulado: Relações literárias interamericanas.

OAB: O seu novo livro, A persistência da memória, (Besouro Box, 2018, 171 p.), aborda uma temática bastante presente em sua produção mais recente: a memória social. Ora, como se sabe desde a famosa conferência de Ernest Renan, de 1882, a construção da nação se alimenta não apenas daquilo que se lembra, mas também daquilo que se esquece. As placas de automóveis do Quebec carregam o lema da província "Je me souviens" (eu me lembro). No entanto, para que a afirmação enquanto québécois se consolidasse foi preciso esquecer que, antes, os quebequenses se designaram canadensesfranceses e, antes disso, canadenses. O que estes processos de memória e esquecimento do Quebec ajudam a compreender sobre o percurso do Brasil enquanto coletividade do novo mundo?

ZB: Acho que a grande lição do comparatismo está em uma frase pronunciada por Octavio Paz: “O conhecimento do outro é um ideal contraditório. Pois ele implica que sejamos outros sem deixar de ser nós mesmos". Foi sempre movida por esse ideal que estudei as culturas e literaturas do Caribe francês e do Quebec, sempre na esperança de melhor entender nossos próprios caminhos e descaminhos, no Brasil, quando se trata de determinar nosso papel entre as comunidades do Novo Mundo. Para essa reflexão as publicações de Gérard Bouchard são fundamentais para guiar qualquer debate nessa área. Se no caso do Québec o lema expresso nas placas dos automóveis: “Je me souviens/eu 
me lembro" faz o observador atento pensar no que mencionas de modo muito oportuno, lembrar e esquecer são inseparáveis e constitutivos de qualquer processo mnemônico, eu acrescentaria, juntamente com Aleida Assmann, que essa oposição binária não abarca toda a complexidade da rememoração: à dicotomia memória/esquecimento soma-se o imaginar, já que os interstícios entre lembrar e esquecer são necessariamente preenchidos pela imaginação criadora. Assim, na leitura que se faz dos percursos das coletividades novas nas Américas, a literatura é de fundamental importância, pois inclui elementos da memória cultural, que recolhe o que diz respeito ao sensível e ao simbólico, incluindo os “pequenos nadas”, como refere a incontornável Régine Robin, desprezados na construção das identidades nacionais.

OBA: Para concluir, professora, passadas quatro décadas de sua introdução no Brasil, o que vem a ser, hoje, os estudos canadenses?

ZB: Esta é a questão que sempre perseguiu aqueles que se dedicam a tais estudos: determinar a especificidade dos assim chamados estudos canadenses/canadian studies/ études canadiennes. Penso que não se trata de uma disciplina propriamente dita, mas de um vasto campo inter e trans disciplinar que, congregando colegas das mais distintas áreas das Ciências Humanas e Sociais, possibilita o ir além, isto é, a ultrapassagem de um determinado campo disciplinar, aproximando, em muitos casos, a cultura canadense da do país de origem dos pesquisadores, favorecendo o enriquecimento recíproco. Acho que em nosso livro que está sendo lançado pelas Presses de l'Université Laval neste final de ano, Patrick Imbert, Rita Olivieri-Godet e eu tentamos, de certa forma, (re)definir os Estudos canadenses quando pensamos o título do coletivo: Espaces et littératures des Amériques: mutation, complémentarité, partage (Espaços e literaturas das Américas: mutação, complementaridade e partilha). Ou seja, seria esse o escopo dos estudos canadenses: refletir sobre os espaços culturais das Américas no sentido da observação de suas mutações, na perspectiva de complementaridade e na esperança do compartilhamento. 


\section{Referências bibliográficas}

ANDRÈS, Bernard. Le texte embryonnaire ou l'émergence du littéraire au Québec: 17641815. Québec Studies, nº 15, 1992-1993, p. 67-76.

. Natureza e fronteiras da narrativa em um corpus em emergência (1764-1839). In: BÉLANGER, Alain; HANCIAU, Nubia; Dion, Sylvie (Orgs.). A América Francesa: introdução à cultura quebequense. Rio Grande : Editora da FURG, 1999, p. 381-398.

BERND, Zilá. Antologia de poesia afro-brasileira: 150 anos de consciência negra no Brasil. Belo Horizonte: Mazza, 2011, 200 p.

. Antologia de poesia negra brasileira. Porto Alegre: AGE, 1992, 153 p.

RENAN, Ernest. Que é uma nação? (Tradução de Samuel Titan Jr.). Plural, v. 4, n. 1 1997, p. 154-175.

\section{Notas}

${ }^{1}$ Mestre em Ciências Sociais pela Pontifícia Universidade Católica do Rio Grande do Sul, Embaixador da francofonia das Américas, do Centre de la francophonie des Amériques, Porto Alegre, RS, Brasil. E-mail: oscar.b5@hotmail.com.

${ }^{2}$ Dados disponíveis em: <http://www.francophoniedesameriques.com/la-francophoniedans-les-ameriques/>. Último acesso: 06 nov. 2018. 